\title{
Growth in Vegetable Production and its Decomposition in Karnataka
}

\author{
Afrin Zainab $\mathrm{Bi}^{* *}$ and Umesh, K.B.
}

Department of Agricultural Economics, University of Agricultural Sciences, Bengaluru, Karnataka, India

*Corresponding author: afrinzainab22@gmail.com (ORCID ID: 0000-0002-3979-3277)

Received: $15-01-2021$

Revised: 23-02-2021

Accepted: 27-02-2021

\begin{abstract}
Vegetables are important constituents of Indian agriculture and nutritional security. Along with health benefits, vegetables help in flourishing countries economy, as it provides a great opportunity for income and employment generation for the farming sector. The study has an objective to understand the extent of growth each vegetable experiencing and to derive the major factor for the growth in Karnataka, utilizing time-series data. The total area showed an increasing trend over the period with about $40 \%$ increase in a span of two decades. However, figures for increased production were more appealing than its area, as it has shown $60 \%$ increase. Total production of vegetables in Karnataka has increased from 42 lakh tonnes in 1998-99 to 68 lakh tonnes in 2018-19, with an annual growth rate of $3.9 \%$. The highest growth in production was observed in onion (7.5\% annually) followed by tomato and cole crops. The area effect was the most responsible factor for increasing production of tomato, onion, guards, cole crops and other vegetables group. Thus, in effect for overall vegetables, it is $66 \%$ of the total increased production effect. However, for potato and leafy vegetables, only yield effect was found to be positively contributing to the production.

\section{Highlights}

(- Escalation in vegetable production is majorly contributed by increased in its area rather than increase in yield.
\end{abstract}

$\overline{\text { Keywords: Vegetables, Compound growth rate, area effect, production effect and decomposition analysis }}$

Vegetables are important constituents of Indian agriculture and nutritional security due to their short duration, high yield and value, nutritional richness, economic viability and ability to generate on-farm and off-farm employment. Post green revolution, substantial growth in the country's vegetable production was observed. Growth of area under vegetables in India was reported to be negative during 1991-92 to 1995-96, but it has increased to $4.13 \%$ for period between 2001-02 to 2005-06 (Harish et al. 2015). However, in the last few years vegetables have principal share contributing more than $50 \%$ of the total horticulture area. (Horticultural Statistics at a Glance 2018). Birthal et al. (2007) presented evidence of gradual diversification of Indian agriculture towards high- value crops. Share of land allotted for vegetables had positive relation with household size, however negatively related to land allotted for fruits and size of household. Rao and Joshi (2009) reported that expanding urbanisation together with higher economic growth and changes in the tastes and preferences are causing shift in the food basket in favour of high-value food commodities like fruits, vegetables, milk, meat, egg and fish. These changes in the food basket leading to transformation of the agricultural production portfolio away from food

How to cite this article: Afrin Zainab Bi and Umesh, K.B. (2021). Growth in Vegetable Production and its Decomposition in Karnataka. Economic Affairs, 66(1): 79-84.

Source of Support: None; Conflict of Interest: None 
grains towards high value food commodities. The trend is expected to be continued as the factor influencing would remain more are less similar in the future as well Vanitha et al. (2013) reported phenomenal increase in vegetable area in the country which was about $300 \%$, production by $900 \%$ and productivity by $300 \%$ for the period of six decades. Vegetables are forms a major constituent in country agriculture production and nutritional security because of their characters such as short duration, high yield high nutritional, economic viability. It also provides ample opportunity for generation of on-farm and off-farm employment. However, Un-even growth between the regions and the states was observed for area as well as production (Vanitha et al. 2013). The present study was designed with a specific objective to report the extent of growth each vegetable or vegetable group experiencing and to derive the major factor for the growth. A time-series data required for the purpose was collected from the Department of Horticulture, Bengaluru, Karnataka, for the period 1998-99 to 2017-18 pertaining to area, production and productivity of all the vegetables for Karnataka state.

\section{MATERIALS AND METHODS}

\section{Estimation of Growth in Area, Production and Yield}

In the present study, compound growth rates of area, production and yield for vegetables/ vegetable groups were estimated to study the growth in area, production and yield of these crops. However, compound growth rates were used for the study. Compound growth rates were estimated with the following exponential model.

$$
\begin{aligned}
& Y=a b_{t} \\
& \log y=\log a+t \log b \\
& C G R(\%)=(\text { Anti } \log b-1) * 100
\end{aligned}
$$

where, $C G R=$ Compound growth rate, $t=$ Time period in year, $y=$ Area or production or productivity, $a \& b=$ Regression parameters. The ' $t$ ' test is be applied to test the significance of ' $b$ '.

\section{Decomposition analysis}

To measure the relative contribution of area and yield to the total output change for the major crops, the decomposition analysis model as given below is used. Sharma and Subramanyam (1984) redeveloped the model and several researchers (Kalamkar, 2002) used this model to study growth performance of crops. The method states that, if $A_{\sigma^{\prime}}$ $P_{0}$ and $Y_{0^{\prime}}$ respectively represent area, production and productivity in base year and $A_{n^{\prime}} P_{n}$ and $Y_{n}$ are values of the respective variable in $n^{\text {th }}$ year item.

$$
\begin{aligned}
& P_{0}=A_{0} * Y_{0} \text { and } \\
& P_{n}=A_{n}^{*} Y_{n}
\end{aligned}
$$

Where, $A_{0}$ and $A_{n}$ represent the area and $Y_{0}$ and $Y_{n}$ represents the yield in the base year and $\mathrm{n}^{\text {th }}$ year, respectively,

$$
\begin{aligned}
& P_{n}-P_{0}=\Delta P \\
& A_{n}-A_{0}=\Delta A
\end{aligned}
$$

From equation (1) and (2) we can write,

$$
P_{0}+\Delta P=\left(A_{0}+\Delta P\right)\left(Y_{0}+\Delta Y\right)
$$

Hence,

$$
P=\frac{A_{0} \Delta Y^{*} 100}{\Delta P}+\frac{Y_{0} \Delta A^{*} 100}{\Delta P}+\frac{\Delta Y \Delta A^{*} 100}{\Delta P}
$$

Production $=$ Yield effect + area effect + interaction effect

Thus, the total change in production can be decomposed into three components viz., yield effect, area effect and the interaction effect due to change in yield and area.

\section{RESULTS AND DISCUSSION}

\section{Growth in area, production and yield over time}

Area, production and yield of vegetables in Karnataka from 1998-99 to 2017-18 have been presented in Fig. 1. The total area showed an increasing trend over the period with about 40 per cent increase in a span of two decades. Diversification of agriculture towards high-value crops, especially fruits and vegetables are the contributing factor to this increase (Birthal et al. 
Table 1: Area under production of vegetables in Karnataka

\begin{tabular}{|c|c|c|c|c|c|c|c|}
\hline \multirow{2}{*}{ Crops } & \multicolumn{2}{|c|}{ 1998-99 } & \multicolumn{2}{|c|}{ 2008-09 } & \multicolumn{2}{|c|}{ 2017-18 } & \multirow{2}{*}{$\begin{array}{l}\text { Annual growth rate } \\
(\%)\end{array}$} \\
\hline & Area (ha) & Percent & Area (ha) & Percent & Area (ha) & Percent & \\
\hline Potato & 40675 & 14.81 & 77042 & 23.77 & 35527 & 9.38 & $-2.5^{*}$ \\
\hline Tomato & 38138 & 13.89 & 46038 & 14.20 & 64254 & 16.96 & $3.4^{*}$ \\
\hline Onion & 91008 & 33.15 & 134534 & 41.51 & 195276 & 51.53 & $3.6^{* *}$ \\
\hline Gourd & 17057 & 6.21 & 19566 & 6.04 & 28358 & 7.48 & 2.8 \\
\hline Cole crops & 14333 & 5.22 & 15685 & 4.84 & 19471 & 5.14 & $3.6^{*}$ \\
\hline Leafy Vegetables & 18105 & 6.59 & 15770 & 4.87 & 17776 & 4.69 & -0.1 \\
\hline Other Vegetables & 55241 & 20.12 & 15481 & 4.78 & 18289 & 4.83 & $-8.0^{0 * *}$ \\
\hline Total & 274557 & 100.00 & 324116 & 100.00 & 378951 & 100.00 & $1.8^{*}$ \\
\hline
\end{tabular}

Note: ${ }^{* * *}, * *$ and $*$ indicates significance at $1 \%, 5 \%$ and $10 \%$ levels, respectively.

Table 2: Production of vegetables in Karnataka

\begin{tabular}{|c|c|c|c|c|c|c|c|}
\hline \multirow[b]{2}{*}{ Crops } & \multicolumn{2}{|c|}{ 1998-99 } & \multicolumn{2}{|c|}{ 2008-09 } & \multicolumn{2}{|c|}{ 2017-18 } & \multirow{2}{*}{$\begin{array}{l}\text { Annual growth } \\
\text { rate (\%) }\end{array}$} \\
\hline & $\begin{array}{l}\text { Production } \\
\text { (tonnes) }\end{array}$ & Per cent & $\begin{array}{l}\text { Production } \\
\text { (tonnes) }\end{array}$ & Per cent & $\begin{array}{l}\text { Production } \\
\text { (tonnes) }\end{array}$ & Per cent & \\
\hline Potato & 513415 & 12.00 & 435039 & 8.57 & 509353 & 7.41 & -0.5 \\
\hline Tomato & 901795 & 21.07 & 1504753 & 29.63 & 2081594 & 30.28 & $5.3^{* *}$ \\
\hline Onion & 1335888 & 31.21 & 2158283 & 42.49 & 2986593 & 43.45 & $7.5^{* *}$ \\
\hline Gourd & 227110 & 5.31 & 297836 & 5.86 & 432323 & 6.29 & $3.8^{*}$ \\
\hline Cole crops & 266679 & 6.23 & 297324 & 5.85 & 386285 & 5.62 & $3.9^{*}$ \\
\hline Leafy Vegetables & 178061 & 4.16 & 156717 & 3.09 & 197582 & 2.87 & 1 \\
\hline Other Vegetables & 856967 & 20.02 & 228966 & 4.51 & 280151 & 4.08 & $-9^{* * *}$ \\
\hline Total & 4279915 & 100.00 & 5078918 & 100.00 & 6873881 & 100.00 & $3.9^{* *}$ \\
\hline
\end{tabular}

Note: ${ }^{* * *}, * *$ and $*$ indicates significance at $1 \%, 5 \%$ and $10 \%$ levels, respectively.

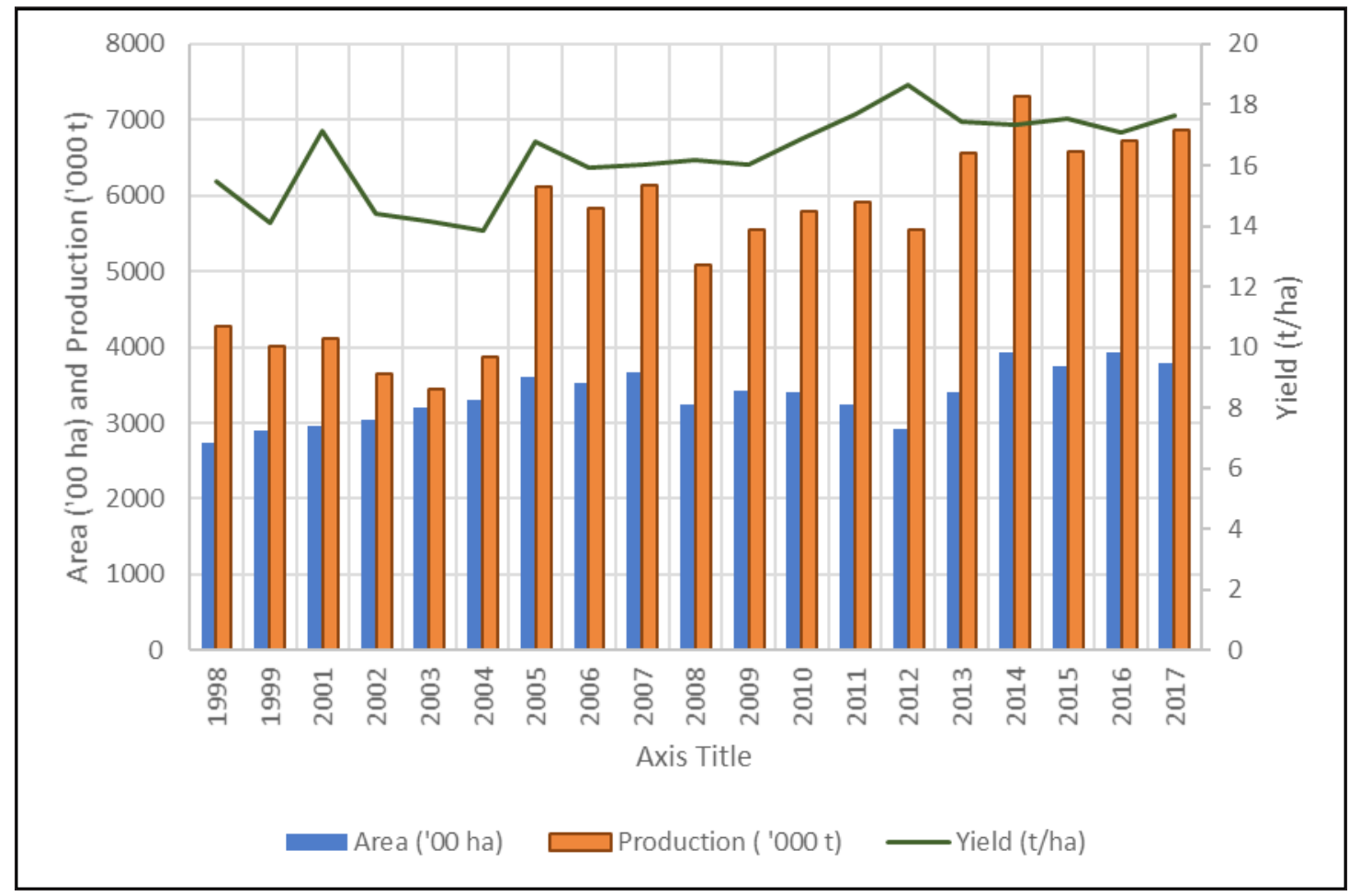

Fig. 1: Area, production and yield of vegetables in Karnataka 
Table 3: Productivity of vegetables in Karnataka (MT/ha)

\begin{tabular}{lllll}
\hline Year & $\mathbf{1 9 9 8 - 9 9}$ & $\mathbf{2 0 0 8 - 0 9}$ & $\mathbf{2 0 1 7 - 1 8}$ & Annual growth rate (\%) \\
\hline Potato & 12.62 & 5.65 & 14.34 & $2^{*}$ \\
Tomato & 23.65 & 32.69 & 32.40 & $1.9^{*}$ \\
Onion & 14.68 & 16.04 & 15.29 & $3.9^{* *}$ \\
Gourd & 13.31 & 15.22 & 15.25 & $1^{*}$ \\
Cole crops & 18.61 & 18.96 & 19.84 & 0.3 \\
Leafy Vegetables & 9.83 & 9.94 & 11.12 & 1.2 \\
Other Vegetables & 15.51 & 14.79 & 15.32 & -1 \\
\hline Total & $\mathbf{1 5 . 4 6}$ & $\mathbf{1 6 . 1 8}$ & $\mathbf{1 7 . 6 5}$ & $\mathbf{2 . 2}^{*}$ \\
\hline
\end{tabular}

Note: ${ }^{* * *},{ }^{* *}$ and ${ }^{*}$ indicates significance at $1 \%, 5 \%$ and $10 \%$ levels, respectively.

Table 4: Decomposition analysis of production effect of vegetables in Karnataka between 1998 and 2017

\begin{tabular}{lllll}
\hline Crops & $\begin{array}{l}\text { Total effect } \\
\text { (tonnes) }\end{array}$ & $\begin{array}{l}\text { Yield effect } \\
\text { (per cent) }\end{array}$ & $\begin{array}{l}\text { Area effect } \\
\text { (per cent) }\end{array}$ & $\begin{array}{l}\text { Interaction effect } \\
\text { (per cent) }\end{array}$ \\
\hline Potato & 28210 & 362 & -230 & -31 \\
Tomato & 1179799 & 28 & 52 & 20 \\
Onion & 1650705 & 3 & 93 & 4 \\
Gourds & 205213 & 16 & 73 & 11 \\
Cole crops & 119606 & 15 & 80 & 5 \\
Leafy Vegetables & 19521 & 119 & -17 & -2 \\
Other vegetables & -576816 & 2 & 99 & -1 \\
\hline Total & $\mathbf{2 4 4 3 7 3 0}$ & $\mathbf{2 5}$ & $\mathbf{6 6}$ & $\mathbf{9}$ \\
\hline
\end{tabular}

2007 and Vanitha et al. 2013). However, figures for increased production were more appealing than its area, as it has shown 60 per cent increase. Yield per unit area under vegetables has increased by 14 per cent in 20 years. Improvement in yield of varieties and/ or hybrids, better farm management practices and increased area under irrigation could be the reasons for enhancement in yield levels.

Area under vegetables for periods between 199899 to $2017-18$ is depicted in table 1 . The vegetable area has reported a spike from 2.7 lakh ha to 3.7 lakh ha, with an annual growth rate of 1.8 per cent. However, the growth is not positive for all the vegetables, viz., potato, leafy vegetables, and other vegetables have recorded a negative growth rate. Among vegetables, onion had the highest area under production followed by tomato and potato. But, Percent share of onion to the total vegetable area in the state has raised from 33 per cent to 51 per cent, the same has fallen for potato (from 14\% to $9 \%$ ). As hypothesized, area under total vegetable production has increased over the period. Thus, the research hypothesis was accepted on the basis of evidences provided above.
Total production of vegetables in Karnataka has increased from 42 lakh tonnes in 1998-99 to 68 lakh tonnes in 2018-19, with an annual growth rate of 3.9 per cent (Table 2).

The highest growth in production was observed in onion (7.5\% per annum) followed by tomato, cole crops and gourds. Similar to the area trend, production share of potato and other vegetables group has fallen significantly, which could majorly attribute to the low profitability of such crops.

Yield per hectare of vegetables grown for three periods is presented in table 3 . Overall, productivity of vegetables has increased at 2.2 per cent annually, yet, other vegetables group has witnessed fall in its productivity with annual rate of -1 per cent. Among all vegetables tomato has highest productivity (32 $\mathrm{MT} / \mathrm{ha}$ ) and leafy vegetables has least productivity (11 MT/ha). This implies that efforts to increase productivity is highest in tomato and least in leafy vegetables.

\section{Output decomposition in vegetables}

Relative contribution of components to aggregate 


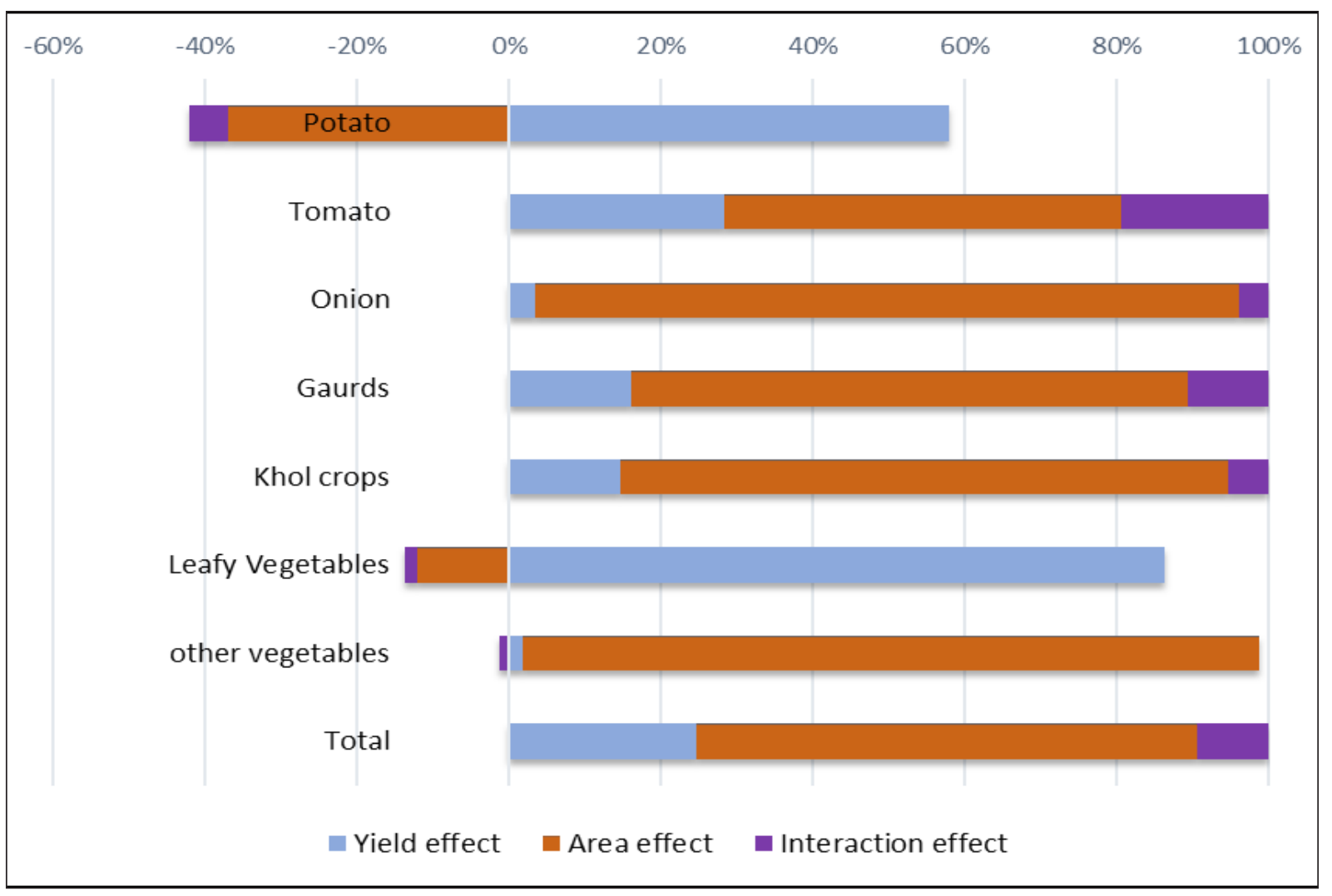

Fig. 2: Decomposition analysis of vegetable production in Karnataka

growth of vegetable in Karnataka output was decomposed into yield effect, area effect and the interaction effect and it is presented in table 4. It demonstrates the per cent contribution of area, yield and their interaction for increasing production of vegetables over the period of 20 years. It is evident from the results that the area effect was most responsible factor for increasing production of tomato, onion, guards, cole crops and other vegetables group. Thus, in effect for overall vegetables, it is 66 per cent. On the contrary area effect is negative for potato and leafy vegetables to the extent of -230 per cent and -17 per cent. These results are contrary to the findings of Anonymous (2008), which stated agriculture growth at national level was attributed to the yield effects.

Yield effect was found responsible for an increase in production of potato and leafy vegetables (362\% and $119 \%$, respectively). In neither of the vegetable's interaction effect of area and yield has a major share in total production effect, representing a lack of synergies between them. After normalizing the components of total production effect to 100 per cent, individual effects are presented in Fig. 2.

\section{CONCLUSION}

In conclusion, Majority of vegetables have witnessed positive growth both in area and production. The exceptions include potato and other vegetables group, potato had negative significant growth in area and other vegetables group had negative growth in both area and production. Decomposing the total production effect of vegetables revealed that positive area effect is more prominent than positive yield effect. Hence, increasing production in future should be aimed through improving productivity, as another option of area expansion has restrictions by the increased human dwelling and other economic development activities. Further it could also be achieved through vertical farming, which is popular for land productivity.

\section{REFERENCES}

Anonymous. 2018. Horticulture statistics at a glance 2018, Ministry of Agriculture and Farmers' Welfare, Government of India.

Birthal, P.S., Joshi, P.K., Roy, D. and Thorat, M. 2007. Diversification in Indian agriculture towards high-value crops: The Role of Smallholders. IFPRI Discussion Paper 00727. 
$\underset{A \text { AESRA }}{\mathbb{U}}$ Afrin and Umesh

Harish, K.K., Amit, K. and Mathur, V.C. 2015. Temporal and Spatial Performance of Horticultural Crops in India. Eco. Affa., 60(3): 367-373.

Kalamkar, S.S. 2003. Agricultural Development and source of output growth in Maharashtra state. Artha Vijnana, XLV(3\&4): 297-324.

Roy, P.P. and Joshi, P.K. 2009. Does Urbanisation influence agricultural activities? A case study of Andhra Pradesh. Ind. J. Agril. Eco., 64(3): 401-408.
Vanitha, S.M., Chaurasia, S.N.S., Singh, P.M. and Naik, P.S. 2013. Vegetable Statistics. Technical Bulletin No. 51, IIVR, Varanasi.

Sharma, P.V. and Subramanyam, S. 1984. A note on the decomposition of the growth rate of aggregate crop output. Agril. Situation in India, 39(9): 691-694. 